\title{
A primeira manifestação do crescimento econômico ocidental: a Europa feudal dos séculos XI-XIII
}

Hilário Franco Júnior

Doutor em História pela USP

Apesar de a historiografia já há alguns anos recomendar a utilização dos instrumentos conceituais de ciências afins, concretamente, na sua elaboração, isso tem sido feito de forma limitada no que diz respeito à Economia. Tal se deve em parte ao fato dos historiadores, mesmo aqueles que circulam com desenvoltura no território de outras ciências ligadas à sua, de maneira geral sentirem maiores dificuldades quando se trata de lidar com o material do economista. Assim, por muito tempo a História Econômica limitou-se a um farto levantamento de dados, apresentado de maneira descritiva, sem dele se tirar conclusões significativas. Mesmo após a mudança dessa postura, a historiografia, ao menos em relação à Idade Média, hesita em aplicar, ou o faz timidamente, os utensílios fornecidos pela ciência econômica (1).

(1) - Os principais dos poucos exemplos são: Cipolla, C. Currency depreciation in medieval Europe, The Economic History Review (EHR) 15, 1963. p. 413-422; Fournial, E. L'indexation des créances et des rents au XIV siècle, Le Moyen Age 69, 1963, p. 583-596; Fourquin, G.', Histoire économique de l'Occident médiéval, Paris, Armand Colin, 1969; Hodgett, G., História social e econômica da Idade Média, trad. port., Rio, Zahar, 1975 (ed. original, 1972); 
E claro que se os homens dos séculos XI-XIII cultivavam a terra, criavam animais, vendiam e compravam diversas mercadorias, transformavam matérias-primas, contraíam e concediam empréstimos, aumentavam ou diminuiam sua riqueza pessoal, não o faziam combinando estas atividades conceitualmente no que chamamos Economia. Em função disso, levantaram-se fortes argumentos contra a aplicabilidade a outras sociedades de teorias e conceitos econômicos formulados para o sistema capitalista (2). Contudo, fazê-lo não significa vermos um determinado período pela ótica do nosso tempo, moldá-lo à nossa imagem e semelhança, mas sim, graças a um aparelhamento intelectual mais sofisticado, penetrarmos mais profundamente numa dada realidade histórica passada.

Desta forma, o que nos propomos a fazer aqui é tentar ultrapassar a fórmula correspondente empregada em relação aos séculos XI-XIII, que fala na "transição de uma economia agrícola de subsistência para uma economia de mercado". Ou seja, pretendemos ver se é possível - em termos conceituais da Economia - detectar na Europa Ocidental daquele período, a ocorrência do fenômeno conhecido por crescimento econômico. Para tanto utilizaremos os dados levantados pela historiografia especializada, apenas organizando-os e interpretando-os de acordo com nosso objeto do estudo. Não é necessário recordar as várias dificuldades para tanto, representadas sobretudo pela escassez de dados quantitativos e pela sua difícil manipulação, já que os dados disponíveis são esparsos, incompletos, setorializados e regionalizados. Tampouco é preciso observar que não se quer mensurar o crescimento econômico, mas apenas verificar sua ocorrência naquele momento. De fato, rigorosamente falando, aquele fenômeno econômico é o aumento do Produto Nacional Bruto per capita (3), ou, em outros termos, acréscimo do produto total mais que proporcional ao aumento da população. Ora, não há como se estabelecer o montante do PNB em relação a uma época para a qual não se pode falar em "economias nacionais", e para a qual as cifras sobre população são apenas estimativas.

Contudo, pode-se detectar a ocorrência do crescimento econômico na Cristandade Latina dos séculos XI-XIII desde que se estando consciente das limitações deste estudo: para nós, nesse caso, PND é apenas

Roehl, R., Pautas y estructura de la demanda, 1000-1500 in Cipolla, C. (org.) Historia económica de Europa. La Edad Media, trad. esp., Barcelona, Ariel, 1981, p. . 115-151.

(2) - Georgescu-Roegen, N., Analytical Economics, Cambridge (Mass.), Harvard University Press, 1966.

(3) - Easterlin, R. A. Economic growth, in International Encyclopedia of Social Sciences, Nova York Macmillan, 1968 IV, p. 402; Bannock, G.R.E. Baxter e R. Rees The Penguin Dictionnary of Economics, Harmondsworth, Penguin, $2^{\mathrm{a}}$ ed., 1978 , p. 144 
um conceito nacional; procuramos indícios do crescimento, e não números para quantificá-lo; deve-se ter em mente que para aquele período qualquer generalização implica possivelmente em muitas exceções. Sobretudo, é importante notar que a Europa católica de então apresentava diversos matizes econômicos, de relações em que o setor primário ainda predominava de forma quase absoluta a outras em que os setores secundário e terciário tinham um grande peso e podiam mesmo, eventualmente, prevalecer. De qualquer forma, "é possível reunir evidências impressionísticas para construir um quadro razoavelmente coerente, que pode ser descrito em termos da teoria moderna" (4). Enfim, pode-se verificar a presença de "um crescimento econômico prolongado e considerável na Europa antes do século XIV" (5) a partir da constatação de que vários de seus processos resultantes e característicos ocorriam então: a) expansão do meio circulante e a consequente inflação de demanda; b) alta dos preços e dos salários; c) modificação na organização da estrutura de produção; d) deslocamento de parte da mão-de-obra agrícola para os setores secundários e terciário; e) crescimento populacional.

a) Após séculos de deflação e entesouramento (6), desde o século $X$ e mais claramente do XI, o volume de metal nobre em circulação na Cristandade Ocidental passou a crescer.O resultado, diante de uma economia que apresentava ainda baixa produtividade, foi uma inflação que se classifica como de demanda, ou seja, uma inflação provocada por um poder monetário de compra maior do que a oferta agregada de bens e serviços, isto é, maior do que a capacidade de produção da economia.

A expansão do meio circulante é facilmente atestada pelas reformas monetárias empreendidas desde o início do século XIII, como forma de se adaptar à nova conjuntura. De fato, na economia tendente à subsistência da Alta Idade Média, tinha sido suficiente o monometalismo de prata, com moedas de pequeno valor intrínseco, que circulavam ainda em pequena quantidade; o denarius de prata correspondia àquela situação econômica contraída (7). Contudo, as necessidades criadas por uma crescente economia comercial levaram Veneza em 1202 a criar uma moeda de prata de valor bem maior, o matapan, correspondente a 24 denaril. Anos depois tal iniciativa foi seguida por várias outras cidades italianas e ainda

(4) - Hodgett, G., op. cit., p. 107.

(5) - Spengler, J. J. in Hoselitz, B. F. (org.), Theories of Economic Growth, Nova York, Free-Press, 1960, p. 3.

(6) - Doehaerd, R., Le haut Moyen Age occidental, Paris, PUF, 1971, p. 325, acredita que a fraqueza demográfica da Alta Idade Média era responsável pela sua "escassez endêmica", de forma que "a exiguidade da produção determina a exiguidade da circulação monetária e a imobilização do metal precioso". Cf. também Fournial, E., Histoire monétaire de l'Occident médiéval, Paris, Fernand Nathan, 1970, p. 53.

(7) - Fournial, E., op. cit., p. 77. 
por Montpellier, Flandres, Inglaterra, Polônia e França (8). Em suma, as novas peças expressavam uma "circulação monetária muito mais abundante" (9).

A grande novidade, no entanto, "a verdadeira revolução monetária do século XIII é a retomada da cunhagem do ouro nas regiões em que ele havia sido abandonado desde o século VIII" (10). Iniciada em 1231 na Sicília (os augustales de Frederico II), ponto de encontro das civilizações bizantina, muçulmana e ocidental, a cunhagem de ouro logo difundiu-se: 1246 em Luca, 1252 o genovino de Gênova e o florin de Florença, 1257 o penny de ouro na Inglaterra, 1259 em Perusia, 1266 o escudo de São Luís, 1284 o ducado de Veneza (11). Assim, entende-se a alta do valor do ouro verificada em 1250-1320 (12). Poder-se-ia estranhar a demora em o sistema monetário acompanhar o progresso econômico, cunhando-se peças de ouro apenas no século XIII, mas tal teria se devido, segundo Gino Luzzatto, à larga difusão no Ocidente de moedas de ouro bizantinas e muçulmanas (13).

Desta forma, chegamos naturalmente à questão central: quais as fontes responsáveis pela expansão do meio circulante? Antes de tudo, a recolocação em circulação dos metais preciosos entesourados. Depois, uma circulação mais rápida daqueles metais. Por último, o estoque metálico ocidental crescia graças ao comércio com o Oriente e ao progresso da mineração. Realmente, como mostrou Renée Doehaerd, a Alta Idade Média ao contrário do que se disse, não foi pobre em ouro, apenas ele estava entesourado devido à pequena oferta de bens, o que fazia a moeda não ser usada tanto como meio de troca quanto instrumento de reserva. "Vários fatores contribuem, portanto, no sentido de uma limitação da massa monetária e no sentido de sua circulação particularmente lenta. não se gasta porque há poucas ocasiões de gastar" (14).

(8) - Idem, ibidem, p. 78-80 Grierson, Ph., Monnaies du Moyen Age, Friburgo, Office du Livre, 1976, p. 162-163.

(9) - Bloch, M., Esquisse d'une histoire monétaire de l'Europe, Paris. Armand Colin, 1954, p. 37.

(10) - Fournial, E. op. cit., p. 80.

(11) - Idem, ibidem, p. 80-81; Grierson, Ph., op. cit., p. 163-175.

(12) - Fourquin, G., op. cit., p. 183.

(13) - Luzzatto, G., Storia economica d'Italia. Il Medioevo. Florença, Sansoni, 1973, p. 280. Fournial, E., op. cit., p. 73-76, discorda desta posição, argumentando que as escavações revelaram poucas moedas bizantinas e muçulmanas no Ocidente, apesar das muitas referências a elas nos textos. Contudo, lembrando que aquelas moedas a) poderiam ter sido refundidas no próprio Ocidente, fornecendo metal para as novas espécies monetárias então criadas; b) poderiam, muito provavelmente, ter servido a pagamentos das compras feitas no Oriente; c) podem ainda vir a serem descobertas em maior quantidade pois a arqueologia medieval encontra-se ainda em desenvolvimento, inclinamo-nos a pensar que é preferível basearmo-nos nos textos, e acompanharmos a posição de Luzzatto.

(14) - Doehaerd, R., op. cit., p. 316 e 324. 
Este estoque metálico da Alta Idade Média, esterilmente poupado sob a forma de jóias, lingotes ou mesmo moedas, naturalmente foi recolocado em circulação quando o crescimento populacional pressionando por uma maior produção reativou toda a atividade econômica. Assim, ou através da compra de várias mercadorias ou do financiamento de certos negócios, aquele metal foi reinjetado na economia. $\mathrm{Na}$ verdade, a recolocação do metal precioso em circulação já havia começado lentamente no período anterior, com os saques efetuados pelos vikings (15). Claro está que o peso desse fator foi variável conforme as regiões: na Provença, por exemplo, tudo indica que não havia grandes quantidades de metais nobres entesourados, de forma que o inegável crescimento do volume monetário provinha em grande parte do comércio a longa distância, através dos lombardos (16).

Tão importante quanto o fato de grande parcela do estoque metálico ter voltado a desempenhar seu papel de instrumento de troca, foi a aceleração da velocidade de circulação das moedas existentes. De fato, a oferta monetária só poderia se alargar com o aumento do volume de metal amoedável ou com sua circulação mais intensa. Como apesar do regulamento econômico e do consequente enfraquecimento do entesouramento ainda havia "escassez monetária" (17), a forma de compensar em parte este problema foi através de uma circulação mais rápida (18). Em suma, o desenvolvimento das trocas, o rápido ritmo da circulação de mercadorias, superior ao crescimento do volume monetário, precisou ser acompanhado por uma velocidade monetária correspondente (19).

Também contribuiu no sentido do alargamento do meio circulante a importação de metais nobres dos mundos muçulmano e bizantino através do comércio. É bastante conhecida a tese de Maurice Lombard, segundo a qual os muçulmanos além de se apossarem de grandes estoques de ouro acumulados durante séculos nas regiões por eles conquistados, contavam com a produção de ouro novo, proveniente da África Ocidental. No circuito comercial da época, os muçulmanos tinham uma balança comercial favorável em relação a Bizâncio, para onde reexportavam mercadorias asiáticas, mas desfavorável em relação ao Ocidente cristão de onde importavam escravos, metais, madeira para construção naval. Assim, ocorria um fluxo de ouro muçulmano para a Cristandade latina

(15) - Duby, G., Guerriers et paysans, Paris, Gallimard, 1973, pp. 136-137.

(16) - Poly, J-P., La Provence et la société féodale, Paris, Bordas, 1976, p. 238-249.

(17) - Fournial, E., op. cit., p. 71.

(18) - Fourquin, G., op. cit., p. 179. 1977 , p. 113.

(19) - Antonetti. G., A economia medieval, trad. port., São Paulo, Atlas, 
(20). Contestando a cronologia daqueles fatos - e reforçando assim nosso ponto de vista - Etienne Fournial afirma que "o grande período do ouro muçulmano não começa no século IX para se fechar no XI; ele começa no XII para acabar por volta de meados do XIII" (21).

Como o Império Bizantino, a Europa cristã teve por muito tempo uma balança comercial desfavorável, devido às compras de seda, especiarias. cereais e produtos de luxo orientais, sendo o déficit coberto com a remessa de metais preciosos. A partir do século $\mathrm{X}$, no entanto, e cada vez. mais. mercadores ocidentais, sobretudo italianós, conseguiram vários privilégios comerciais em território bizantino, invertendo o sentido do fluxo monetário. De forma clara desde 1204, com a conquista latina de Constantinopla, os ocidentais passaram a dominar a economia bizantina (22), só com o saque da capital naquela oportunidade colocando nas mãos dos ocidentais inúmeras relíquias e obras de arte, grande quantidade de ouro e prata. Na descrição de um participante, "rouba-se uma enorme quantidade de cavalos, de ouro e de prata, de tecidos de seda, de ricas vestimentas, de pedras preciosas e de tudo que os homens consideram como riquezas" (23).

Por fim, a extração mineira foi outra fonte de metais amoedáveis, ainda que menos importante que os fatores examinados anteriormente. De qualquer forma, desde fins do século $\mathrm{X}$ exploravam-se os filões de chumbo argentífero sob as colinas de Rammelsberg, perto de Goslar, no Harz. Mais tarde descobriu-se um veio de minério com teor de prata bem superior na cidade de Freiberg, na Saxônia, que se tornou grande centro minerador, atraindo pessoas de todos os locais e atingindo por volta de 1170 cerca de 30.000 habitantes (24). No entanto, além

(20) - Lombard, M., O ouro muçulmano do VII ao XI século. As bases monetárias de uma supremacia econômica, Revista de História 6, 1953, p. 25-46.

(21) - Fournial, E., op. cit., p. 75.

(22) - Franco Jr, H., Uma interpretação da economia bizantina, Revista de História 56, 1977, p. 38-40.

(23) - Carta do conde Balduino ao arcebispo de Colônia apud, Walter, G. La ruina de Bizancio, trad. esp., Barcelona, Martinez Roca, 1970, p. 113. Descrições semelhantes em Geoffioy de Villeharduin ( $L a$ conquête de Constantinople, ed. A. Pauphilet, Historiens et Chroniqueurs du Moyen Age, Paris, Gallimard, 1952 , LV, p. 146): "o ganho foi tão grande que ninguém poderá dizer a quantidade de ouro e de prata, e de vasos e pedras preciosas, e de tecidos de seda e de roupas claras e escuras e de peles e de todas as coisas caras como jamais foram encontradas noutro local"; e em Robert de Clari (La conquête de Constantinople ed. A. Pauphilet, op. cit., LXXXI, p, 72): "ali havia tão ricas baixelas de ouro e de prata, e tecidos de ouro e tão ricas jóias que era uma maravilha. Não creio que nas quarenta cidades mais ricas do mundo houvesse tantos bens como se encontraram em Constantinopla".

(24) - Forbes, R. J., Metallurgy in Singer, C. (org.), A History of Technology, Oxford, Clarendon, 1956. II, p. 65. 
da Europa central, apenas a Inglaterra apresentava uma produção mineira considerável, pois boa parte do continente era pobre em minérios, com veios superficiais que logo se esgotavam, tornando necessária a escavação de poços mais profundos, com melhor drenagem e madeiramento, fatores que requeriam um maior investimento de capital e tornavam a atividade mineradora menos interessantes economicamente (25).

Assim, com metal precioso de diversas origens, sob pressão de uma demanda sempre maior, passou-se a cunhar mais moedas a partir do século XI. Se por volta de 1075 na Europa meridional os documentos mostram que os preços estipulados em moeda apresentavam também sua equivalência em gado ou em gêneros - expressão de um uso ainda tímido e intermitente da moeda - em torno de 1140 tal prática desapareceu (26). Desprezando-se as disparidades regionais, podemos afirmar que desde então a Europa católica entrou definitivamente na fase de economia monetarizada, mesmo com a zona rural utilizando cada vez mais a moeda (27), pois diante de uma crescente oferta agregada, a moeda graças à sua liquidez tornou-se $\mathrm{o}$ bem possibilitador da aquisição de qualquer outro bem.

Essa expansão do meio circulante, como já dissemos, gerou uma inflação de demanda, pois como o preço do capital caiu (devido à maior oferta monetária) em comparação ao da mão-de-obra (apesar de sua crescente oferta, ela era absorvida pela também crescente demanda), os preços dos bens se elevaram, mais no caso daqueles que requereram maior intensidade de mão-de-obra, um pouco menos no dos que pediam na sua produção capital mais intensivo. Além disso, já se sugeriu que nas economias não desenvolvidas a propensão marginal a consumir é mais elevada, expandindo, naturalmente, a demanda e assim realimentando a espiral inflacionária (28). De fato, para Genicot é mais plausível pensar-se para o século XIII num crescimento do consumo superior ao da produção (29).

(25) - Hodgett, G., op. cit., p. 187.

(26) - Herlihy, D. Treasure hoards in the Italian economy, 960-1139, EHR 10,1957, pp. $1-12$.

(27) - Duby, G. L'economie rurale et la vie des campagnes dans l'Occident médiéval, Paris, Aubier, 1962, I, pp. 226-232. Na Inglaterra do século XII as prestações devidas por um grande número de camponeses foram transformadas em rendas monetárias; cf. Postan, M. M., Medieval agrarian society in its prime. England, The Cambridge Economic History of Europe (CEHE), Cambridge, CUP, 1971, I, pp. 605-606, 615.

(28) - Harberger, A. C., The dynamics of inflation in Chile apud Bronfenbrenner $M$. e F. D. Holzman, Um retrospecto da teoria da inflação in American Economic Association-Royal Economic Society, Panorama da moderna teoria econômica, trad. port., São Paulo, Atlas, 1973, I, p. 123.

(29) - Genicot, L., Europa en el siglo XIII, trad. esp., Barcelona, Labor, 1970, p. 284. 
A elevação do nível geral dos preços no período que examinamos pode ser verificada pela aplicação da equação de Fischerer (30). Nela, indica-se por $\mathrm{M}$ a massa monetária em circulação, isto é, a quantidade de moeda disponível, e por $\mathrm{V}$ a velocidade de circulação daquela massa, obtendo-se o produto MV, que representa a fluxo monetário total do sistema. O outro elemento da equação é o produto PT, que representa - valor global das transações realizadas no sistema, indicando-se por $\mathrm{P}$ o nível dos preços e por $\mathrm{T}$ o volume dos bens e serviços produzidos. Assim, sua formulação é $M V=P T$. Oro, se, como queremos crer, já provamos a ocorrência da expansão monetária (certo aumento no volume de moeda multiplicado por um giro monetário mais acelerado), resta agora mostrar que a variável $\mathrm{T}$, ainda que se elevando em relação à da Alta Idade Média, fê-lo menos que proporcionalmente que MV, de forma que a igualdade da equação só pôde ser obtida pela elevação de P.

Precisamos examinar sobretudo o setor primário, que fornecia a maior parte da produção e assegurava a subsistência de - no caso da Inglaterra, que porém pode ser considerado típico - três quartos da população (31). Apesar da parca documentação e de sua difícil interpretação, podese fazer uma idéia aproximada da produtividade da cerealicultura da Alta Idade Média: Slicher Van Bath (32) considera como relação média entre sementeira e colheita 1 para 3, enquanto Georges Duby (33) discorda daqueles cálculos e chega a relação quase sempre inferiores a 1 para 2. No século XIII, para o primeiro daqueles autores (34) a média era no caso do trigo $1: 4$, da cevada $1: 3,5$, da aveia $1: 3$ e do centeio $1: 5,5$. Por sua vez, Duby (35) acredita que por volta de 1300 o colhido fosse três ou quatro vezes o semeado. Nas terras do bispado de Winchester a média era de 4, 2 (36).

Portanto, comparando-se os dois períodos, o aumento teria sido de menos de $40 \%$ para o estudioso holandês e de um pouco mais de $50 \%$ para o francês. Como entre os dois períodos ocorreu um crescimento populacional mais que proporcional ao aumento da produção - como vemos pela tabela I. a população européia teria mais do que duplicado entre 1000 e 1300 - isso significa que a produtividade não cresceu com-

(30) - Trevithick, J. A. Inflation, Harmondsworth, Penguin, 1979, pp. 17-21.

(31) - Postan, M. M., The medieval economy and society, Harmondsworth, Penguin, 1978, p. 259.

(32) - Slicher Van Bath, B. H., Historia agraria de Europa occidental, trad. esp., Barcelona, Peninsula, 1974, p. 96.

(33) - Duby, G., op. cit., I, pp. 84-87.

(34) - Slicher Van Bath, B. H., op. cit., p. 254.

(35) - Duby, G., op. cit., I, p. 187.

(36) - Calculado a partir de dados extraídos de Titow, J. Z., Winchester yields: a study in medieval agricultural productivity, Cambridge, CUP, 1972, pp. 14, 48-49 e 148 . 
parativamente ao período anterior, pelo contrário. Por outro lado, sem dúvida os setores secundário e terciário se ampliaram, inclusive com aumento da produtividade, mas devido à sua pequena participação no produto total da Cristandade (com um destaque maior apenas na Itália do norte e Flandres) não chegaram a modificar a variável $\mathrm{T}$ na mesma proporção de MV. E importante insistir para o fato de que apesar de Georges Duby acreditar que após 1180 a agricultura até então "motor de todo o desenvolvimento" tornou-se secundária, vindo o predomínio da economia urbana (37), na realidade ela continuou, indubitavelmente, a ser o setor básico da economia européia até princípios do século XIX e em alguns casos por mais tempo ainda.

TABELA I

Evolução demográfica da Cristandade Ocidental do ano 1000 ao 1300 (em milhões de habitantes)

$\begin{array}{lcccc}\begin{array}{l}\text { PAÍSES } \\ \text { (segundo as fronteiras }\end{array} & 1000 & 1100 & 1200 & 1300 \\ \begin{array}{l}\text { atuais) } \\ \text { Itália }\end{array} & 5,0 & 5,75 & 7,25 & 10,0 \\ \text { Alemanha } & 3,5 & 4,0 & 6,0 & 9,0 \\ \text { Holanda } & 0,3 & 0,4 & 0,6 & 0,8 \\ \text { Belgica e Luxemburgo } & 0,4 & 0,6 & 0,9 & 1,25 \\ \text { Suiça } & 0,3 & 0,4 & 0,5 & 0,8 \\ \text { França } & 6,5 & 7,75 & 10,5 & 16,0 \\ \text { Inglaterra e Gales } & 1,5 & 1,75 & 2,5 & 3,75 \\ \text { Espanha } & 4,0 & 4,5 & 5,5 & 7,5 \\ \text { Portugal } & 0,6 & 0,7 & 0,9 & 1,25 \\ \text { Totais } & 22,1 & 25,85 & .34,65 & 50,35\end{array}$

Fonte: McEVEDY, C. e R. JONES, Atlas of world population history, Har. mondsworth, Penguin, 1980, pp. 49-106.

Infelizmente os dados que possuímos sobre a elevação geral dos preços no período aqui considerado são escassos e fragmentários, não permitindo um tratamento quantitativista. De qualquer forma, a Inglaterra - que neste sentido apresenta sempre uma documentação mais rica - fornece-nos algumas indicações preciosas, que não temos razão para acreditar que sejam atípicas. Naquele país, em fins do século XII, segundo lord Beveridge, ocorria uma verdadeira "revolução dos preços medieval" (38). Em 1250-1299 os preços eram três vezes superiores

(37) - Duby, G. Guerriers et paysans, p. 300.

(38) - Citado por Postan, M. M., op. cit., p. 262. 
aos de 1200-1249 e apenas 15\% mais baixos que em 1300-1349 (39). Em suma, verificou-se um trend inflacionário da década de 1160 à de 1320, com seu pico em torno do ano de 1200: no primeiro decênio do século XIII o preço de bois era $118 \%$ mais elevado do que em 1160 , o de ovelhas $132 \%$, o de vacas $155 \%$ e, superando os demais aumentos, $264 \%$ o do trigo (40).

Michel Postan, no entanto, não aceita a expansão circulante como causa da inflação na Inglaterra, argumentando que o fluxo de metais nobres para aquele país teria sido pequeno devido a um balanço de pagamentos poucas vezes favorável; que a chegada daqueles metais não aumentaria necessariamente o volume da massa monetária devido ao entesouramento; que os metais não eram os únicos meios de pagamento por já se recorrer aos instrumentos de crédito (41).

Porém, Harvey mostrou que em 1180-1220 o valor da prata caiu na Inglaterra a um terço do que fora anteriormente, por causa do grande volume daquele metal que entrou no país em troca das exportações de tecidos, estanho, trigo e sobretudo lã; a contraprova é encontrada no fato de que com os gastos militares de Ricardo Coração-de-Leão e JoãoSem-Terra no continente, e a consequente saída de metal precioso, a alta de preços se interrompeu (42).

Na medida que era o comércio o responsável pela chegada de metal amoedável, parece pouco provável que os negociantes seus possuidores entesourassem-no ao invés de reinvestí-lo. Mesmo ordens religiosas, como a dos cistercienses, os maiores criadores de gado ovino da Inglaterra, procuravam desenvolver seus negócios (43). Ademais, o conteúdo de prata da moeda inglesa, superior ao das demais, prova o destino que se dava ao metal: os denarii de Tours, Gênova e Milão continham menos que um quarto e o de Veneza menos que um dezesseis avos do conteúdo de

(39) - Hamilton, E. J., Price History, in International Encyclopedia of Social Sciences, $12, \mathrm{p}, 471$.

(40) - Miller, E. e J. Hatcer, Medieval England. Rural society and economic change, (11086-1348, Londres, Longman, 1978, pp. 67-68.

(41) - Postan, M. M., op. cit., pp. 266-269. Noutro estudo o mesmo autor (The trade of medieval Europe: the North CEHE, II, p. 167) afirma que a alta de preços atingiu apenas os gêneros alimentícios, o que parece pouco provável, pois o encarecimento dos produtos primários sem dúvida exerce pressão no mesmo sentido sobre os demais bens. Por outro lado, como observou Hervey, P. D. A. (The English inflation of 1180-1220, Past and Present, 61, 1973, p. 17) se apenas o preço do trigo e do gado tivessem aumentado, a prosperidade das cidades deveria ter diminuido, o que não acnotceu.

(42) - Harvey, P., op. cit., pp. 26-29.

(43) - Donkin, R. A., Cattle on the estates of medieval Cistercian monasteries in England and Wales, EHR 15, 1962-1963, p. 45. 
prata do penny (denarius) inglês (44). Por fim, não se pode esquecer que os instrumentos de crédito só funcionavam como meio de pagamento por terem lastro metálico que garantiu seu poder liberatório, além do que, obviamente, alargavam ainda mais o meio circulante.

b) Como a demanda se expandiu mais que proporcionalmente que a oferta, houve uma alta dos preços que provocou uma alta nos lucros e a consequente ampliação dos negócios, com o decorrente alargamento da procura no mercado da mão-de-obra, que resultou naturalmente numa alta também dos salários. Assim, os assalariados passaram a dispor de rendas monetárias maiores, que elevaram o valor monetário de sua procura por bens e serviços. Tal elevação significou uma demanda agregada que continuava a exceder a oferta agregada, resultando em nova alta dos preços e na inevitável pressão pela expansão da produção, o que elevou mais uma vez o preço do trabalho, isto é, os salários. Portanto, o valor monetário da demanda dos trabalhadores por bens e serviços subiu outra vez, repetindo-se o processo. Enfim, ocorria, como vimos, uma inflação de demanda, já que "os preços reagem muito mais rapidamente ao excesso da demanda do que ao excesso da oferta" (45).

Em primeiro lugar, devemos considerar o setor primário, básico nas sociedades pré-industriais, daí a importância do preço de cereais, "barô-

Tabela II

\begin{tabular}{cc} 
Evolução dos índices dos preços do trigo inglês (1160-1339) \\
ANOS & INDICES \\
$1160-1179$ & 100 \\
$1180-1199$ & 139,3 \\
$1200-1219$ & 203,0 \\
$1220-1239$ & 196,1 \\
$1240-1259$ & 214,2 \\
$1260-1279$ & 266,9 \\
$1280-1299$ & 279,2 \\
$1300-1319$ & 324,7 (devido à fome \\
$1320-1339$ & \multicolumn{2}{c}{ de 1315-1317) }
\end{tabular}

FONTE: Indices calculados a partir dos dados de lord Beveridge, citados por POSTAN, M. M. The trade of medieval Europe: the north CEHE II, 166.

(44) - Cipolla, C., Currency depreciation in medieval Europe, p. 422.

(45) - Bruton, H. Principios de economia do desenvolvimento, trad. port., São Paulo, Atlas, 1969, p. 108. 
metro da situação econômica geral" (46). Sendo a oferta de alimentos inelástica, ou seja, de elevação da produção proporcionalmente inferior à dos preços, num momento de crescimento populacional e portanto de maior demanda, os preços cerealíferos naturalmente apresentavam tendência altista, provavelmente superior à elevação média dos preços. Os índices dos preços do trigo na Inglaterra, que constam da tabela acima, provam aquela tendência.

Apesar das variações sasonais e regionais, claramente o período 1150-1300 presenciou uma elevação dos preços de cereais (47), responsável em parte pelo alargamento da área cultivada. Tal movimento, na verdade iniciado por volta de 1050 , foi responsável pelo maior crescimento da superfície cultivável visto na Europa desde os tempos pré-históricos (48), processo ocorrido sobretudo no século XII, "o momento culminante dos arroteamentos" (49). A ocupação de novas terras permitiu o aumento da produção a custo relativamente baixo, de forma que enquanto o custo marginal foi inferior à receita marginal, havia interesse na abertura de novas áreas à agricultura. Apenas no século XIV, com o retrocesso populacional e com custo marginal superior, o processo cessou, pois ocorria então a chamada lei dos rendimentos decrescentes: devido à fixidez da capacidade tecnológica, a aplicação de mais unidades de recursos resultava em aumentos menos que proporcionais na capacidade produtiva.

Nos setores secundário e terciário observou-se a mesma tendência altista. No entanto, apesar do valor médio do volume de produção por trabalhador naqueles setores ser maior que no primário, os preços de seus bens e serviços se elevaram a um ritmo menos intenso, por utilizarem na sua produção uma proporção maior de capital (cujo preço estava em baixa) e menor de mão-de-obra (cujo preço estava em alta) comparativamente à agricultura. Este dado não deve, porém, ser exagerado: no setor têxtil, o mais importante da indústria medieval, a mão-de-obra representava $60 \%$ do custo final $(50)$. Se os preços agrícolas estavam sujeitos a fortes oscilações, devidas a variaçōes climáticas por exemplo, os preços industriais - sobretudo o têxtil, setor que absorvia boa parte da mão-de-obra e dos capitais industriais - eram mais sensíveis às flutuações (51). Tal se devia, em parte, aos problemas políticos-sociais, comuns nos centros industriais flamengos e italianos.

(46) - Slicher Van Bath, B. H., op. cit., p. 143.

(47) - Idem, ibidem, pp. 154 e 184.

(48) - Bloch, M., Les caractères originaux de lhistoire rurale française 2. Paris, Armand Colin, 1976, I, p. 5.

(49) - Duby, G. L'économie rurale, I, p. 146. 1975, p. 104 .

(50) - Gimpel, J., La révolution industrielle du Moyen Age, Paris, Seuil, (51) - Postan, M. M., op. cit., p. 259. 
Quanto aos salários, Slicher van Bath (52) observa que sua curva acompanhava a dos preços cerealíferos, de forma que elas se comportavam como se uma fosse reflexo da outra; portanto, em 1150-1300 assistimos à elevação dos preços de cerais e dos salários reais. Por sua vez, Postan acredita que na Inglaterra do século XIII o crescimento demográfico e a consequente maior oferta de mão-de-obra tenha, provavelmente, feito caior os salários reais (53).

Tal posição, no entanto, considera a questão apenas do lado da oferta, esquecendo-se da expansão geral dos negócios e portanto da forte demanda por mão-de-obra. De qualquer forma, os dados que possuímos indicam no sentido da elevação salarial: nos domínios do bispado de Winchester e da abadia de Westminster, os salários reais de joeirador e de debulhador eram em 1320 de 25 a $40 \%$ menores que em 1210 (54); Henrique II pagava por dia 8 denarii por cavaleiro e um denarius por infante, enquanto por volta de 1200 aquelas cifras tinham passado a 2 ou 3 shillings por cavaleiro e 2 denarii por infante; outros salários apontam ainda para a mesma direção (55). Na Itália, comparando-se os salários de artesão em 1228 com os de 1300 . verifica-se que os últimos eram um pouco superiores, porém provavelmente o aumento era nominal e não real (56), o que significa que antes da situação excepcional criada na segunda metade do século XIV pela Peste Negra, os níveis salariais mais altos ocorreram no período de expansão econômica.

c) A ocorrência de modificações na organização da estrutura de produção, outro acompanhante do crescimento econômico, também é detectável na Europa católica dos séculos XI-XIII. De fato, em toda economia naquele estágio verifica-se que $\mathrm{o}$ tamanho das unidades produtivas cresce (seja a medição em mão-de-obra ou volume de produção), assim como a divisão do trabalho dentro das unidades produtivas e entre elas (57), fatos facilmente verificáveis na Cristandade daquela época.

No setor agrícola, uma primeira modificação, resultante da pressão demográfica e do melhoramento da produção, foi a fragmentação dos mansos, que "implicava portanto no declínio das corvéias e no desaparecimento do regime dominial carolíngio" (58). Claro está que este processo precisa ser matizado, pois enquanto na Normandia o manso desapareceu

(52) - Slicher Van Bath, B. H., op. cit., p. 150.

(53) - Postan, M. M., op. cit., p. 257.

(54) - Idem, ibidem, p. 274.

(55) - Harvey, P., op. cit., pp. 13-14 e 17.

(56) - Leicht, P. S., Operai, artigiani, agricoltori in ltalia dal secolo VI al XVI, Milão, Giuffrè, 1946, p. 122.

(57) - Hagen, E., Economia do desenvolvimento, trad. port., São Paulo, Atlas, $1971, \mathrm{I}, \mathrm{p} .68$.

(58) -- Antonetti, G., op. cit., p. 61. 
prematuramente, talvez desde o século $\mathrm{X}$, na Inglaterra a hide resistiu até o século XIII. Da mesma forma, a reserva senhorial teve sua área reduzida, com parte dela sendo desmembrada em novas tendências camponesas, fato tornado possível pelo uso de novas técnicas agrícolas e consequente melhoria do rendimento: "o abastecimento do senhor e de seus familiares exigia doravante áreas cultivadas menores" (59). Assim, se 0 tamanho das unidades produtivas rurais diminui em termos de área, cresceu quanto à força de trabalho empregada e/ou ao volume produzido.

Outra alteração verificada na economia rural daquele período foi concernente ao regime de trabalho. A mão-de-obra servil estava em retração, com a corvéia que a caracterizara sendo reduzida a mero reforço para algumas tarefas sasonais, chegando mesmo algumas vezes a desaparecer. Para Georges Duby (60), nas regiōes meridionais as corvéias já eram leves no século XIII, enquanto nas setentrionais eram claramente mais pesadas, ainda que menores que no século IX, com exceção dos senhorios eclesiásticos ingleses onde sua importância mantinha-se significativa. De qualquer forma, no conjunto, presenciava-se um recuo das prestações em serviço comutadas por taxas monetárias, expressão da nova conjuntura econômica. Devido à crescente monetarização da economia e à maior oferta de mão-de-obra, a utilização de trabalhadores assalariados tornava-se mais comum, substituindo aos poucos aos servos domésticos e aos servos com tenências (servi casati). Em outros casos, desejando os senhores um rendimento fixo, arrendavam parte da terra, costume que se manifestou inicialmente na Flandres, norte da França, norte da Itália e Inglaterra, regiões de amplo tráfico monetário, generalizando-se no século XIII (61).

Ainda no setor primário, deve-se lembrar da crescente especialização, pois com o desenvolvimento do comércio e a possibilidade de se obter com alguma facilidade as mercadorias necessárias, cada região procurava explorar melhor suas potencialidades, sem a preocupação da Alta Idade Média com a autarcia. Assim, por exemplo, a viticultura conheceu grandes progressos, sobretudo nos vales do Reno, do Mosela, do Mosa, na Borgonha e na Aquitânia. Esta produção pedia muitos cuidados e muita mão-de-obra, mas a demanda por ela era crescente, não só devido à elevação do padrão de vida de certos segmentos da sociedade ocidental, mas também à necessidade litúrgica. Desta forma, nos locais de clima e solo fovaráveis, e sobretudo próximos às vias de exportação, a viticultura progrediu, com o vinho constituindo-se num dos principais produtos

(59) - Fourquin, G., Histoire économique, p. 195, e Le paysan d'Occident au Moyen Age, Paris, Fernand Nathan, 1972, p. 113.

(60) - Duby, G., op. cit., II, pp. 424-434.

(61) - Slicher Van Bath, B. H., op. cit., p. 220. 
do comércio internacional (62): no início do século XIV a Gasconha exportava anualmente cerca de 80 a 100.000 tonéis de vinho (63), a maior parte dirigindo-se para a Inglaterra que importava então perto de 90.000 tonéis $(64)$.

Da mesma forma, certas regiões de solo pouco propício para a lavoura passaram a dedicar-se à criação de gado cavalar para a guerra, bovino para os trabalhos agrícolas, suíno para a alimentação e ovino para o fornecimento de lã, matéria-prima básica para a indústria têxtil em expansão. Os preços em contínua elevação certamente contribuiam para a difusão da pecuária; o preço da lã, sobretudo, não só acompanhava o nível geral de preços, mas beneficiava-se ainda da crescente demanda $\mathrm{e}$ às vezes de problemas na oferta, como na década de 1270 o aparecimento de uma epidemia de sarna nos rebanhos ingleses (65). Para alguns autores, como Postan, o progresso da criação teria implicado mesmo na retração das áreas cultivadas (66). Se tal afirmativa é discutível, não resta dúvida, contudo, que o rebanho europeu deve então ter atingido números bastante expressivos: em 1086, em três condados ingleses havia 12 carneiros e 3 porcos por camponês, além de bois, cabras e cavalos, mas em proporção bem inferiores (67); em 1270-1280 nos domínios do mosteiro cisterciense de Melsa havia 11.000 carneiros (68); nos domínios do bispo de Chichester havia 3150 cabeças de gado em 1220 e 5900 no século XIV (69); em meados deste século só de gado ovino havia cerca de 8 milhões de cabeças na Inglaterra e 1,5 na Espanha (70).

No setor secundário verifica-se a mesma tendência. $O$ crescimento das unidades produtivas fica claro no fato de anteriormente boa parte da produção artesanal provir das oficinas senhoriais, satisfazendo apenas as reduzidas necessidades locais, enquanto na época aqui examinada as oficinas se multiplicaram atendendo a uma demanda bem maior, tanto nos centros urbanos quanto na zona rural. Também ao contrário do que

(62) - Renouard, Y. Grand commerce des vins de Gascogne au Moyen Aeg, Revue Historique, 221, 1959, pp. 301-302 e O grande comércio de vinho na Idade Média, Revista de História, 6, 1953, p. 314.

(63) - James, M. K., Studies in the medieval wine trade, Londres, OUP, 1971, pp. 9-10.

p. 244 .

(64) - Postan, M., The trade of medieval Europe: the North, CEHE, II,

(65) - Lloyd, T. H., The movement of wool prices in medieval England, Cambridge, The Economic History Society, 1973, p. 15.

(66) - Postan, M., Village livestock in the thirteenth century, EHR 15, 1962-1963, pp. 219-249.

(67) - Rarby, H. C., The Domesday geography of eastern England, Cambridge, CUP, 1952, pp. 199 e 255.

(68) - Donkin, R. A., op. cit., p. 34.

(69) - Duby, G., op. cit., I, p. 248.

(70) - Antonetti, G., op. cit., pp. 41-42. 
acontecia antes - quando, de forma geral, cada artesão realizava todas as etapas do processo produtivo e confeccionava diferentes bens, com exceção de uma ou outra atividade que exigia maior especialização nos séculos XI-XIII a divisão do trabalho tornou-se uma realidade, sobretudo na indústria têxtil, onde a produção dava-se em 26 eatpas diferentes, cada uma realizada por artesãos especializados (71). Mais para o fim da Idade Média, fora portanto do período aqui considerado, mas certamente prolongando uma tendência anterior, cidades de porte médio contavam com muitas corporaçôes, expressão da divisão social do trabaiho, caso de Perúgia com 44 arti e Verona com 48; nos grandes centros aquele número crescia, chegando a $142 \mathrm{em}$ Veneza (72). Indubitavelmente aumentou muito também o número de pessoas empregadas pela indústria: em Florença de princípios do século XIV a produção têxtil lanífera utilizava o trabalho de umas 30.000 pessoas (73). A intensidade do fenômeno era naturalmente muito maior nas zonas urbanas da Itália e Flandres, daí os exemplos acima, mas fazia-se presente em quase todas as regiões devido às inevitáveis necessidades de existência de uma indústria têxtil e de construção (74).

Igualmente, o setor terciário expandia-se. Se nele a especialização é menos clara, apesar da existência de associações mercantis dedicadas à venda de uns poucos bens, sem dúvida o volume de negócios cresceu extraordinariamente em relação ao período anterior. Isto é atestado, por exemplo, pela crescente tonelagem dos navios - ainda que a tonelagem total pareça-nos hoje espantosamente pequena (75) - dado significativo já que o transporte marítimo e fluvial superava em muito o volume de mercadorias deslocado por terra, onde o frete era bem mais caro. Ainda assim muitas vias terrestres eram abertas ou melhoradas: só na França dos séculos XI-XIII foram construídas 375 pontes (76). Portanto, "do fim do século $X$ aos anos 1300 , o volume do comércio, melhor seria dizer dos comércios crescem em proporções realmente consideráveis. Todos os fatos, todas as fontes concordam permitindo ao historiador afirmá-lo. Mas a pobreza dos documentos com cifras torna impossivel qualquer tentativa de avaliação e de mensurar os progressos quantitativos" (77).

(71) - Gimpel, J., op. cit., p. 103; cf. também. Gille, B., Le moyen Age occidental in Daumas, M. (dir.), Histoire générale des techniques, Paris, PUF, 1962, I, pp. 525-534.

(72) - Leicht, P. S., op. cit., p. 108.

(73) - Carus-Wilson, E. The woolen industry, CEHE, II, p. 393.

(74) - Hodgett, G., op. cit., p. 150.

(75) - A frota veneziana totalizaria apenas cerca de 40.000 toneladas:

Le Goff, J., La civilisation de l'Occident médiéval, Paris, Arthaud, 1967, p. 272.

(76) - Dado extraído da lista de pontes francesas medievais apresentada por Boyer, M. N., Medieval French Bridges, Cambridge (Mass.), The Medieval Academy of America, 1976, pp. 171-195.

(77) - Fourquin, G., op. cit., p. 268. 
d) Diante da tendência altista dos preços e dos salários, do alargamento da demanda global e da consequente expansão dos negócios, os setores secundários e terciários conheceram grande progresso, atraindo parte da força de trabalho do setor primário. Ademais, com o crescimento populacional a agricultura não conseguia absorver toda a oferta de mão-de-obra (apesar do fracionamento dos mansos e do arroteamento de novas áreas), levando então muitos trabalhadores a procurarem atividade nos centros urbanos. De fato, a elevação da renda per capita gerou uma mudança na demanda que por sua vez provocou uma mudança na produção: as despesas com alimentos sobem menos rapidamente que a despesa global, isto de forma acentuada nas rendas mais altas onde o consumo de moradia, roupas, transporte, educação e lazer são bem maiores. Noutros termos, a elasticidade-renda da demanda de alimentos é menor do que a unidade, embora ela aumente à medida que a renda se eleva, enquanto para outras despesas a elasticidade é maior do que a unidade (78). Portanto, à medida que a renda sobe, a procura, a partir de certo ponto, passa de bens do setor primário para os do secundário e depois do terciário.

Além disso, como sabemos, os preços dos bens que requereram capital mais intensivo (caso da produção secundária e terciária) subiram menos que os demais, de forma que, supondo alguma elasticidade-preço - relação entre as modificações porcentuais ocorridas na oferta ou na procura decorrentes de alteraçōes porcentuais verificadas nos preços - para a maioria dos bens de consumo, a demanda daqueles bens produzidos com intensidade maior de capital elevaram-se mais rapidamente do que a dos bens produzidos com maior intensidade de mão-de-obra (79). Como, paralelamente, a agricultura apresentava sua tendência de entrar na fase de rendimentos decrescentes mais rapidamente, verificava-se êxodo de camponeses em busca de setores ainda em expansão.

Mais ainda, crescia a poupança, sobretudo em locais de setores secundários e terciários mais desenvolvidos, o que aumentava a oferta de capital, barateando-o - no decorrer do século XIII, na Itália, a taxa média de juro caiu de $20-26 \%$ para $8-12 \%$, "prova da abundância do dinheiro e do crédito" (80) — e assim alargando a demanda por bens provindos dos setores secundários e terciário. De fato, poupava-se mais por ocorrer então a chamada lei de Engel: as parcelas reservadas às despesas de consumo crescem em valor absoluto à medida que aumenta o montante da renda disponível, mas a sua porcentagem em relação a esta

(78) - Hagen, E., op. cit., I, p. 72.

(79) - Bruton, H., op. cit., pp. 96-97 e 116.

(80) - Lopez, R., Naissance de l'Europe, Paris, Armand Colin, 1962, p. 306. e The trade of medieval Europe: the south, CEHE, II, p. 334. 
última decresce constantemente (81). Em outras palavras, recorrendo-se à terminologia Keynesiana, a propensão a consumir reduz-se à medida que a renda aumenta e, mais ainda, a propensão marginal a consumir (relação entre renda marginal e consumo marginal) é menor quanto maior a renda, ou seja, os acréscimos de consumo tornam-se menos expressivos nos níveis de renda mais altos, o que eleva a propensão marginal a poupar.

Portanto, o desenvolvimento da indústria, do comércio e do sistema bancário provocou a intensificação da vida urbana - surgiram cerca de 140 novas cidades entre 1100 e 1300 (82) - que atraía trabalhadores oriundos do campo, não só pela esperança de um padrão de vida superior, mas até de mudança de condição social. Quase sempre o direito urbano não aceitava a servidão, de forma que residindo numa cidade um ano e um dia, o servo passava a ser considerado livre, como indica o célebre provérbio medieval, Stadtluft macht frei (83). Ao menos as obrigaçōes devidas eram reduzidas, como, para citar um caso dentre inúmeros outros, em Laon a mão-morta e a formariage desapareceram e a talha foi trans formada em pagamento fixo; de forma geral a talha arbitrária e a corvéia eram abolidas (84). Porém, mais uma vez, infelizmente, não possuímos documentação que forneça cifras sobre esta migração campo-cidade, de forma a podermos comprovar quantitativamente nossa afirmação.

No entanto, há razões para acreditarmos que ela seja verdadeira. Não se pode negar a significativa expansão populacional das cidades por volta do ano 1000 possivelmente não existisse na Cristandade Latina nenhuma cidade que chegasse aos 10.000 habitantes, enquanto no século XIII 55 delas ultrapassavam aquela cifra (85) - nem se pode com verossimilhança atribuí-la unicamente ao seu crescimento vegetativo. Para se ter um ponto de partida para alguns cálculos estimativos, adotemos a taxa média anual de crescimento de $0,46 \%$ que foi estabelecida para a Inglaterra de 1086 a 1346 por Josiah Russel (86). Se admitirmos, sem fazer disso uma lei demográfica, mas como uma hipótese de trabalho bastante plausível, que as populações urbanas crescem em geral a taxas

(81) - Rossetti. J. P., Introdução à Economia, São Paulo. Atlas, 6å ed., 1977 , p. 662 .

(82) - Beresford, M. W., New towns of the Middle Ages, Londres, Butterworth, 1967, p. 328 .

(83) - Ellul, J., Histoire des institutions. Le Moyen Age, Paris, PUF, 7a ed., 1976, p. 207; Lopez, R., op. cit., p. 181: Le Goff, J., op. cit., p. 366; Van Werveke $H,$. , The rise of the towns, $C E H E$ III, p. 18 .

(84) - Stephenson, C., Borough and towns. A study of urban origins in England, Cambridge (Mass.), The Mediaeval Academy of America, 1933, pp. 39 e 45 .

(85) - Lopez, R., op. cit., pp. 267-268 e Genicot, L., op. cit., p. 247.

(86) - Russel, J. C., British medieval population, Albuquerque, University of New Mexico Press, 1948, p. 246. 
maiores que as rurais, e que aquela taxa de $0,46 \%$ é média, podemos talvez aceitar $0,6 \%$ para as cidades. Ora, partindo-se de uma cidade hipotética de 2.000 moradores no início do século XI, ela teria em fins do século XIII, caso não recebesse injeções demográficas provenientes do campo, apenas 9.473 habitantes. Portanto, impõem-se como conclusão que para dezenas de cidades alcançarem cifras superiores àquela, devem ter recebido razoável contingente de camponeses. Como já afirmou um dos maiores especialistas em história rural medieval, "as cidades e vilas cresceram sobretudo pela imigração dos camponeses da vizinhança" (87).

e) Por fim, o drescimento populacional, anterior ao crescimento econômico e num certo sentido seu elemento possibilitador, foi acelerado por este. Realmente, no dizer de um economista (88), "o volume de produção real depende não somente da capacidade da economia em produzir bens e serviços como também da demanda agregada", isto é, as pressões exercidas pelo mercado consumidor sobre os setores produtivos levam estes últimos a procurarem, dentro das possibilidades técnicas da época, expandir seus negócios. $\mathrm{Na}$ verdade, o crescimento econômico medieval resultou mais da mobilização de mão-de-obra que de capital (89), ou seja, foi mais extensivo que intensivo, como fica claro no setor primário, que se manteve como o mais importante da economia. $O$ produto total cresceu graças a um maior número de pessoas trabalhando numa extensão maior de terras (90).

Por outro lado, "um acréscimo na oferta de mão-de-obra elevará sua produtividade média, até que a quantidade relativa tenha passado tão além do ponto de rendimentos decrescentes, que sua produtividade marginal cairá para igualar-se à média" (91). Tudo parece indicar que nas últimas décadas do século XIII já se ultrapassara aquele ponto, daí a queda da produtividade, $O$ abandono das terras menos férteis ocupadas durante o movimento de arroteamentos e mesmo uma ligeira inversão na tendência da evolução demográfica, com sua curva apresentando certo declive (92).

Assim, diante destes elementos todos, acreditamos que se possa falar na ocorrência de um crescimento econômico na Cristandade Ocidental entre

(87) - Duby, G., L'économie rurale, I, p. 223; Guerriers et paysans, pp. 270-271; La société auX XI et XII siècles dans la région mâconnaise, Paris, Touzot, 1971, pp. 269-270.

(88) - Bruton, H., op. cit., p. 38.

(89) - Hodgett, G., op. cit., p. 111.

(90) - Duby, G., Guerriers et paysans, p. 217.

(91) - Hagen, E., op. cti., I, p. 320

(92) - As razões desta parada e mesmo certa regressão demográfica são muito discutidas, com Genicot, L., op. cit., pp. 261-264, defendendo a ocorrência de uma queda no índice de natalidade, enquanto Duby, G., L'économie rurale, I, pp. 216-219, acredita numa elevação da taxa de mortalidade. 
os séculos XI e XIII. Naturalmente, portanto, surge a questão: porque aquele crescimento não se tornou irreversível, alcançando o estágio que os economistas denominam do desenvolvimento econômico? A resposta é simples: os elementos geradores de desenvolvimento econômico, isto é, de crescimento prolongado e contínuo (93) - acumulação de capital e progresso técnico (94) - não chegaram a ocorrer nas intensidades necessárias.

De fato, quase sempre se valoriza o papel do capital no processo do desenvolvimento (95), mas nesta análise deve-se levar em consideração tanto sua oferta quanto sua demanda. Do lado da oferta, o elemento mais importante é a poupança, porém se durante 0 processo de crescimento econômico a porcentagem da riqueza total poupada aumentz tal não ocorre indefinidamente (96). Para as economias industrializadas, concluiu-se que uma poupança líquida anual de 4 a $5 \%$ do Produto Nacional Bruto não gera acumulação de capital e desenvolvimento, mas apenas expansão horizontal de capital, diante de um incremento de 1 ou 1,5\% na força de trabalho (97). Se no período aqui estudado, entre os anos 1000 e 1300 , o crescimento populacional ocorreu a taxas maiores, por sua vez é verossímil pensar que as taxas de poupança eram menores. Mais ainda, a expansão demográfica, grande para os recursos existentes, reduziu a quantidade de capital disponível e o excedente para investimentos, de forma que em fins do século XIII a oferta de capital retraiu-se (98).

Por outro lado, a acumulação de capital é muitas vezes ditada mais pela sua demanda do que pela sua oferta (99), de forma que quando o campo para investimentos é reduzido, limita aquela demanda e portando a acumulação. Foi o que ocorreu na Europa católica dos séculos XI-XIII, onde as possibilidades de inversão eram poucas: na agricultura, a concentração fundiária e a mentalidade tradicionalista, não induziam à poupança; na indústria artesanal, as pequenas unidades produtivas e a rigidez do sistema corporativo demandavam pouco capital; no comércio, devido às perspectivas de bons resultados, as aplicações de capital eram maiores, mas os riscos também, e assim os capitais gerados eram em grande parte imobilizados em fortunas fundiárias (100).

(93) - Bruton, H. op. cit., p. 21.

(94) - Hagen, E. op. cit., I, p. 55.

(95) - Kindleberger, C., Economic development, Nova York, McGraw Hill, 1958, pp. 35-40.

(96) - Hagen, E., op. cit., I, p. 69

(97) - Idem, ibidem, II, p. 372 .

(98) - Hodgett, G., op. cit., p. 120.

(99) - Pepelasis, A., L. Mears e I. Adelman, Desenvolvimento econômico, trad, port., São Paulo, Atlas, 1967, p. 98.

(100) - Duby, G., Guerriers et paysans, p. 291. 
Outro fator a ser levado em consideração é a mentalidade da época; de maneira geral pouco valorizadora de objetos marcadamente materiais. Se há um certo exagero em afirmar-se que "a mentalidade das classes dominantes é antitecnicista", antiprogressista, com horror às novidades (101), não se pode negar que o sistema de valores reinante não favorecia o progresso econômico (102). Como em todas as sociedades pré-industriais, havia a concepção de uma fixidez dos recursos existentes, de forma que as economias eram vistas como relativamente estáticas. Além disso, as idéias eclesiásticas sobre o preço justo e a usura representavam barreiras à plena expansão dos negócios.

Deve-se ainda considerar a forma de emprego do capital, fator fundamental para a sua reprodução: "do ponto de vista do desenvolvimento, a acumulação de capital requer não apenas um excesso de produção sobre o consumo, mas também o investimento destas poupanças em bens de capital produtivo" (103). No entanto, tal não acontecia, em parte devido à inflação, que induz à poupança em bens não produtivos (104), em parte devido ao espírito da época. Neste sentido, Robert Lopez lembra o interessante caso de Beauvais, sede de um rico distrito agrícola e produtor de tecidos da lã famosos em toda Europa, que depois de um início promissor viu sua prosperidade interrompida, sem se beneficiar da prosperidade geral do século XIII, talvez por ter imobilizado grandes capitais na construção de sua imponente catedral (105).

Os gastos não produtivos eram imensos não só na construção e manutenção de castelos e palácios, catedrais e mosteiros, como também em cerimônias laicas e religiosas. Em fins do século XIII a catedral de Canterbury dispendeu 1000 libras com a eleição de um novo prior e 1300 libras com a eleição de um novo arcebispo, parte significativa de seus rendimentos (106). O setor agrícola contribuia com a maior porcentagem do produto total da economia cristã ocidental, mas a maioria dos senhores de terra investia apenas $5 \%$ ou ainda menos, de suas rendas (107). Os camponeses, por sua vez, devido às pesadas obrigações para

(101) - Le Goff, J., La civilisation; pp. 252 e 254.

(102) - Le Bras, G., Conceptions of economy and society, CEHE III, pp. $557-575$.

(103) - Meier, G. e R. Baldwin, Desenvolvimento econômico, trad, port., São Paulo, Mestre Jou, 1968, p. 396.

(104) - Bruton, H.; op. cit., p. 207.

(105) - Lopez, R., Naissance de l'Europe, pp. 270-273, e Economie et architecture médiévales, AESC 7, 1952, pp. 435-436.

(106) - Miller, E. e J. Hatcher, op. cit., p. 231.

(107) - Idem, ibidem, p. 232; Le Goff, J., op. cit., pp. 286-290; Roehl, R.. op. cit., pp. 142-143, também avalia a inversão em 4 ou $5 \%$ mas faz a ressalva de que se tratava de investimento bruto, portanto incluindo uma parte considerável destinada a substituir bens depreciados, de forma que o investimento líquido deveria estar entre 1 e $2 \%$. 
com os senhores pouco podiam fazer em termos de formação de capital, enquanto os lucros comerciais e industriais não eram reinvestidos suficientemente para a reprodução do capital naqueles setores (108).

No que diz respeito à inovação técnica, a Europa cristã medieval também não fez o suficiente para atingir o estágio do desenvolvimento econômico, pois "sem progresso técnico continuado, o crescimento indefinidamente constante não pode ser concebido, em consequência dos rendimentos decrescentes do capital" (109). Ademais, como o progresso técnico tende a elevar o produto marginal do capital, estimulando assim o investimento, sua ausência, ou pequena intensidade, restringia a demanda por capital, fator que dificultava sua acumulação. Os historiadores tem se impressionado com certos dados - num pequeno afluente do Sena em Rouen havia apenas 2 moinhos hidráulicos no século $\mathrm{X}$, número que subiu para 5 no século XII, 10 no XIII e 12 por volta de 1300; na região de Forez só um no início do XII e cerca de 80 no XIII; em Aube 14 no XI, 60 no XII, 200 no XIII (110) - que pouco significam por serem regionalizados e não estarem relacionados com a população, a produção e o investimento.

Apesar de alguns avanços significativos - chegou-se a afirmar que nos séculos XI-XIII a Europa ocidental "conheceu um período de intensa atividade tecnológica e é uma das épocas da história da humanidade mais fecunda em invenções" (111) - que não podem ser negados, devese ter em mente seu limitado alcance. Primeiramente, porque no essencial o progresso técnico foi mais quantitativo que qualitativo (112). Depois, porque houve pequena difusão de muitas inovações. Discordamos de Lynn White Jr. (113) quando ele considera os 5624 moinhos d'água registrados pelo Domesday Book como número expressivo, pois não sabemos exatamente o que significa a relação 1: 196 entre moinhospopulação, já que desconhecemos a energia gerada por aqueles moinhos, a sua produtividade, a sua distribuição geográfica exata, a sua distribuição em termos de propriedade. Igualmente, vemos com reservas sua afirmação - sem fundamentar, e que saibamos sem existir documentação neste sentido - de que a Inglaterra estava atrasada tecnologicamente em relação à Europa continental, implicitamente afirmando que nesta a utilização da força motriz hidráulica seria mais generalizada.

(108) - Hilton, R. H., Rent and capital formation in feudal society, The English peasantry in the later Middle Ages, Oxford, Clarendon, 19756 pp. 213-214.

(109) - Hagen, E., op. cit., I, p. 240.

(110) - Forbes, R. J., Power, in Singer, C. (org.), op. cit., II, p. 609.

(111) - Gimpel, J., op. cit., p. 5.

(112) - Le Goff, J., op. cit., p. 249. 
Não se pode esquecer que a Cristandade Latina ainda permanecia predominantemente uma área de produção e consumo primários, e que naquele setor econômico o surgimento de inovações técnicas foi pequeno (114) e sua difusão deu-se muito lenta (115). Havia, ainda, algumas vezes, resistência às inovações, como por exemplo no caso dos tecelóes de Abbeville, que em 1288 se recusaram a aceitar os fios feitos pelas novas rodas de fiar (116). Desta forma, com o crescimento populacional a produtividade caía, já que a oferta de mão-de-obra tornava-se excessiva em relação aos demais insumos, daí seu produto marginal tender a zero. Como observou Georges Duby, "a despeito das alterações feitas nos últimos anos do século (XIII), o progresso técnico não conseguia atender às necessidade de uma população muito numerosa, que a fome atormentava tão cruelmente quanto talvez nos tempos carolíngios" (117).

Em suma, acreditamos que a afirmação de Everett Hagen - "na Europa ocidental, o crescimento e o desenvolvimento econômicos começaram durante a Idade Média" (118) - e a posição de Guy Fourquin - o take-off rostowiano europeu teria ocorrido na segunda metade do século XV (119) - não sejam defensáveis. Para nós o Ocidente europeu não conheceu o desenvolvimento econômico na Idade Média, mas apenas, assim temos razóes para acreditar ainda que este não seja o local para demonstrá-lo, no século XVIII, graças à acumulação de capital mercantilista e à acumulaçã̃o de conhecimento técnicos verificada desde o século XI e acelerada a partir do XVII.

De qualquer forma, este crescimento econômico, decorrente da própria dinâmica da sociedade feudal, esteve nas raízes das transformações desestruturadoras sofridas por aquela formação social, revelando-se assim um fenômeno histórico de importância fundamental para o período vulgarmente conhecido por "transição do Feudalismo para o Capitalismo".

(113) - White, J. L., Medieval technology and social change, Oxford, Clarendon, 1962, p. 84.

(114) - Duby, G., Guerriers et paysans, p. 214.

(115) - Duby, G., L'economie rurale, I, p. 202.

(116) - Gille, B., Machines, in Singer, C. (org.), op. cit., II, p. 649

(117) - Duby, G., op. cit., I, p. 219.

(118) - Hagen, E., op. cit., I, p. 57.

(119) - Fourquin, G., Histoire économique, p. 430. 